\title{
A PRODUÇÃO CIENTÍFICA SOBRE FELICIDADE EM PERIÓDICOS BRASILEIROS 1
}

THE SCIENTIFIC PRODUCTION ABOUT HAPPINESS IN BRAZILIAN NEWSPAPERS

\author{
CAMPOS, Priscilla Perla Tartartotti von Zuben ${ }^{1}$; FUENTES-ROJAS, Marta ${ }^{2}$ \\ ${ }^{1}$ Universidade São Francisco, Itatiba/SP e Universidade Estadual de Campinas, Limeira/SP; \\ ${ }^{2}$ Universidade Estadual de Campinas, Limeira/SP \\ pptvzc@gmail.com
}

RESUMO. Este artigo tem como propósito apresentar os resultados apurados em uma revisão da produção cientifica sobre felicidade a partir de publicações em periódicos brasileiros indexados na base de dados Scientific Eletronic Library Online (SciELO). Optou-se pela pesquisa quanti-qualitativa na intenção de se verificar quantos estudos sobre o tema felicidade haviam sido produzidos e o que tem sido pesquisado a respeito. Como critério de busca os artigos deveriam conter o descritor "felicidade" como parte do título. A nacionalidade dos autores ou idioma de publicação não foram restringidos, envolvendo-se todas as publicações disponíveis. A amostra totalizou 40 artigos. Averiguou-se que os estudos sobre felicidade são incipientes no país. Também foi possível apurar que as áreas que se interessam em pesquisar felicidade são distintas. Chamou atenção o fato de que a área do trabalho tem recebido notoriedade no que concerne à maior demanda de estudos sobre felicidade. Outra questão que sobressaiu em alguns artigos foi a menção quanto ao despontar da psicologia positiva. Esta investigação visa promover o acesso acerca da forma como o conhecimento sobre felicidade vem sendo consolidado, bem como provocar o avanço deste conhecimento no país. Reconhece-se a necessidade de prosseguir com este estudo e integrar outras bases de dados a fim de apresentar um panorama sobre a felicidade em âmbito nacional e posteriormente internacional. Esta pesquisa se mostra relevante visto que o avanço teórico sobre esta temática tem sido mínimo, assim como as publicações que intentam concentrar evidências e/ou informações científicas no Brasil.

Palavras-chave: revisão sistemática; conhecimento; bem-estar.

ABSTRACT. This article aims to present the results of a review of the scientific production on happiness from publications in Brazilian journals indexed in the Scientific Eletronic Library Online (SciELO) database. Quantitative-qualitative research was chosen in order to verify how many studies on the happiness theme had been produced and what has been researched about it. As a search criterion the articles should contain the descriptor "happiness" as part of the title. The authors' nationality or language of publication were not restricted, and all available publications were covered. The sample totaled 40 articles. It was found that studies on happiness are incipient in the country. It was also possible to verify that the areas that are interested in researching happiness are different. It was noted that the area of work

\footnotetext{
${ }^{1}$ Este manuscrito origina-se de problematizações oriundas de uma dissertação sobre felicidade, em desenvolvimento, junto ao Programa de Mestrado Interdisciplinar em Ciências Humanas e Sociais Aplicadas na Faculdade de Ciências Aplicadas da Universidade Estadual de Campinas. Salienta-se que o estudo sobre felicidade - que se encontra em desenvolvimento - se desdobra em outras pesquisas referente à temática junto ao Programa de Iniciação Científica da Universidade São Francisco em parceria com o Laboratório de Psicologia, Saúde e Comunidade da Universidade Estadual de Campinas.
} 
has received notoriety regarding the greater demand for studies on happiness. Another issue that stood out in some articles was the mention of the emergence of positive psychology. This research aims to promote access to the way knowledge about happiness has been consolidated, as well as to provoke the advancement of this knowledge in the country. It is recognized that it is necessary to continue with this study and to integrate other databases in order to present a panorama of happiness at national and later international level. This research is relevant since the theoretical advance on this topic has been minimal, as well as the publications that attempt to concentrate evidence and / or scientific information in Brazil.

Keywords: systematic review; knowledge; well-being.

\section{INTRODUÇÃO}

Os estudos sobre felicidade oferecem uma oportunidade para discussão e reflexão sobre qual sua concepção social, além de gerarem elementos importantes para fundamentar e nortear o que tem sido acumulado pelos seres humanos em torno deste fenômeno ao longo dos tempos.

Ao acessar e disseminar o que outros estudiosos já produziram, torna-se possível compreender a felicidade sob diferentes prismas, provocar novas problematizações, além de favorecer o encontro de diferentes saberes, de pessoas que se debruçam sobre a temática e centram seus esforços para buscar entende-la, para responder aspectos que a envolvem ao longo dos tempos e outras dimensões distintas. Afinal a questão milenar permanece: O que é felicidade? O que é ser feliz?

Frente aos paradoxos da felicidade vivenciados na contemporaneidade e na busca por respostas de diferentes dimensões em torno dela, evidencia-se neste manuscrito a necessidade de organizar de modo mais coletivo e centrado o conhecimento propagado a seu respeito. Para tanto, realizou-se uma revisão da produção cientifica sobre felicidade a partir de publicações em periódicos brasileiros indexados na base de dados Scientific Eletronic Library Online $\left(\mathrm{SciELO}^{2}\right)$.

Esta base foi escolhida por ser uma biblioteca eletrônica que abrange periódicos científicos selecionados, disponíveis de modo gratuito e de acesso aberto ${ }^{3}$ em todo o mundo. A escolha por artigos em períodos se deu por ser um veículo importante para a disseminação do conhecimento, embora não seja a única. Ademais, entende-se que a comunicação científica tem papel importante, pois divulga pesquisas, identifica os membros da comunidade científica, legitima estruturas e permite o acesso aos programas de fomento, o que viabiliza a legitimidade e consistência da área a partir dos resultados apresentados (SCHWEITZER \& RODRIGUES, 2013).

Atenta ao rigor requerido pela comunidade acadêmica, esta pesquisa se mostra relevante visto que o avanço teórico sobre esta temática tem sido mínimo. Mesmo que ao

\footnotetext{
${ }^{2}$ Um portal para integrar e prover acesso à rede de sites SciELO. Está em operação em http://www.scielo.org. A Rede SciELO é considerada a maior provedora de periódicos indexados pelo Diretório de Periódicos de Acesso Aberto (Directory of Open Access Journals - DOAJ). Disponível em http://www.scielo.org/php/level.php?lang=pt\&component=56\&item=61. Acesso em 27 jan.2016.

${ }^{3} \mathrm{O}$ movimento para acesso livre ao conhecimento científico, segundo Mueller (2006), tem sido importante no que se refere à comunicação científica e precisa ser cada vez mais legitimado a fim de avançar em um processo que permita o acesso livre e crescente ao conhecimento científico. De acordo com a autora, na medida em que isto acontece, mudanças radicais são provocadas no sistema tradicional de comunicação do conhecimento científico e na crença das comunidades científicas.
} 
longo dos séculos filósofos e pensadores reconhecidos tenham buscado estudá-la, pouco se sabe sobre ela. Faz-se esta afirmação sob o respaldo de Sewaybricker (2017), ao mencionar em sua tese sobre os estudos de Wilson e de Bradburn na década de 60, cujos autores avaliam que pouco avanço teórico foi promovido ao longo de seu trajeto desde os filósofos gregos.

Aliado ao avanço teórico restrito em torno da temática, requer-se atentar ao fato de que este tem sido feito sob outro enfoque: como um objeto científico e não filosófico, tal como nos expõe Sewaybricker (2017). A despeito disto, o autor alerta que estudá-la enquanto objeto em constante transformação - tornando-a mensurável, fragmentada e acrescida de novos sinônimos e correlatos - pode conduzir ao abandono de importantes discussões. Afinal, segundo ele, trazer discussões a seu respeito, pode não ser tão promissor quanto "estudá-la enquanto objeto em constante transformação" (p. 5).

Como a felicidade é compreendida no contexto atual? Pensar sobre a felicidade, remete tecer reflexões sobre a forma como a compreensão que se tem dela influencia crenças, emoções e comportamentos. Trata-se de um tema polêmico e polissêmico, com potência para mobilizar indivíduos e grupos frente a empreendimentos antes não imaginados ou ainda, leva pessoas a paralisarem-se diante da simples, porém complexa pergunta sobre o que é felicidade. Estudar a felicidade faz questionar o seu significado em relação à compreensão que se tem dela, seu impacto na vida e na forma como se tem vivido.

Sobre os modos de vida, Lipovestky (2007), ao tratar sobre a crença moderna diante da felicidade, questiona se realmente há progresso no caminho que conduz a ela. De acordo com este autor, é possível que se esteja em um movimento contrário, que direciona à uma crença que leva a confundir bem-estar material e vida feliz. Corroborando com isto, Sewaybricker (2017), aponta que na contemporaneidade é preciso considerar o caráter performativo e líquido em constante transformação, concernente a felicidade.

Para Sewaybricker (2017), a felicidade pode ser percebida como: "aquilo que determinada pessoa entende ser, em dado momento, a melhor forma de se viver a partir de sua relação dialética com o mundo" (p.156-167). Conduz às "receitas de felicidade", formas para prescrever como se deve ser feliz e ao não direito da infelicidade, ou momentos de tristeza. Isto requer cautela e conduz a inquirir sobre como a compreensão que se tem sobre a felicidade na sociedade contemporânea e quais os efeitos disso.

Felicidade é realmente o que se tem chamado de felicidade? Não estaria sendo confundida com bem-estar? Parece que as pessoas têm se distanciado da ideia de felicidade quando a associam à uma concepção moderna sobre ela. Há mais de 2500 anos, o filósofo grego Aristóteles ${ }^{4}$ (384-322 a.C.), ao tratar sobre a felicidade fez menção à tarefa da autorrealização do ser humano em um horizonte partilhado com as virtudes éticas. Em seu tempo, defendeu a felicidade como "o bem supremo e que pode ser obtido através da ação humana" (p.15), sem desconsiderar, de todo modo, questões sobre o sentido do prazer e do sofrimento, formas da excelência ética e do domínio de si.

Trata-se do exercício constante da virtude ética atrelada à persistência para a realização de boas ações, em um processo de refinamento que exige esforço, um continuum permeado por momentos de alegrias e tristezas com vistas ao "Sumo Bem". Com esta ideia, ainda em construção e visando orientar as buscas na compreensão sobre a felicidade, pautadas por "virtudes éticas", nas palavras de Aristóteles (2009), é que esta pesquisa foi realizada.

Considera-se este manuscrito relevante, visto termos poucas publicações que intentam concentrar evidências e/ou informações cientificas sobre a felicidade no país. Sob este prisma,

\footnotetext{
${ }^{4}$ COELHO, Introdução, In.: ARISTÓTELES, 2009, p. 2
} 
a proposta aqui apresentada consiste em revisar de modo sistemático as informações publicadas sobre a temática, as quais venham a contribuir para a intensificação da investigação sobre a felicidade em sua completude - como um fim e não um meio.

\section{METODOLOGIA}

Considerando a importância da produção científica e com a intenção de investigar de modo mais acurado o que tem sido publicado sobre felicidade, realizou-se um levantamento de artigos científicos publicados na base de dados SciELO, utilizando como descritor o termo "felicidade". Foram envolvidas todas as publicações, sendo estas datadas de janeiro de 1981 até dezembro de 2016. Não se restringiu a nacionalidade dos autores, porém foram consideradas apenas artigos publicados no idioma português.

$\mathrm{Na}$ base mencionada, identificaram-se 49 artigos, contudo, com a filtragem inicial, nove artigos foram excluídos. Dois eram repetidos, seis referiam-se a resenhas, um fazia indicações de bibliografias sobre felicidade e um não se caracterizava como produção de artigo. Deste modo, a amostra totalizou 40 artigos. Quanto a análise, inicialmente realizou-se a leitura dos resumos e posteriormente a leitura de outras partes dos artigos na intenção de obtermos maior subsídio sobre a temática da felicidade, para a análise.

Optou-se pela pesquisa quanti-qualitativa na intenção de verificar- quantos estudos sobre o tema felicidade haviam sido feitos a partir da base de dados escolhida, em qual período, por quais áreas de conhecimento, populações estudadas, dentre outros itens, atentas quanto as homogeneidades e heterogeneidades encontradas. Estes dados foram sintetizados na intenção de posteriormente realizar comparações durante o estudo. (GOMES; CAMINHA, 2014).

Para tabular e sintetizar as informações obtidas, uma planilha foi criada e nela foram apontadas categorias para identificar a colaboração entre as diferentes áreas e instituições, tais como: número de autores, nome dos autores, título, ano de publicação, periódico, palavraschave, área do estudo e afiliação institucional.

Para compreender o conteúdo dos artigos, foram geradas as seguintes categorias: questão do estudo, conceito de felicidade, nomenclaturas (nomes utilizados para se referir à felicidade, tais como bem-estar, satisfação), temas de estudo, população-alvo, delineamento (quantitativo, qualitativo, misto) e principais referências utilizadas nos artigos. Assim como, foi gerado um campo para inserir as principais questões que cada artigo provocara em decorrência das leituras feitas.

Nas pesquisas relacionadas à questão inicial deste estudo, foram levadas em conta as similaridades e diferenças importantes entre as pesquisas já realizadas com a finalidade de ampliar as possibilidades interpretativas dos resultados. (GOMES; CAMINHA, 2014). Entende-se que esta revisão sistemática da literatura abrangeu uma revisão integrativa (quantiquali), pois combina um vasto leque de propósitos com perspectivas teóricas, o que gera a possiblidade de olhar o fenômeno da felicidade de diferentes perspectivas.

A intenção foi a de averiguar o que tem sido produzido sobre o assunto, qual a compreensão que se tem dele e como canalizar esforços perante a produção do conhecimento científico a partir de outros estudos, pesquisadores e estudiosos interessados na temática acerca da Felicidade. A seguir são expostos os resultados extraídos desta revisão.

\section{RESULTADOS E DISCUSSÃO}

Dentre os dados apurados apresentam-se aqueles que se mostraram relevantes para 
compreender o que tem sido estudado sobre felicidade. Como pode ser observado na Figura 1, destaca-se: os principais temas de estudo, grupos sociais, áreas de conhecimento interessadas no estudo da felicidade e a ampliação dos estudos sobre felicidade ao longo das décadas. Este último considera-se como "achado" ou resultado não esperado da pesquisa, pois embora a pesquisa tenha ampliada em todas as áreas, os estudos sobre felicidade ainda se revelam incipientes no Brasil.

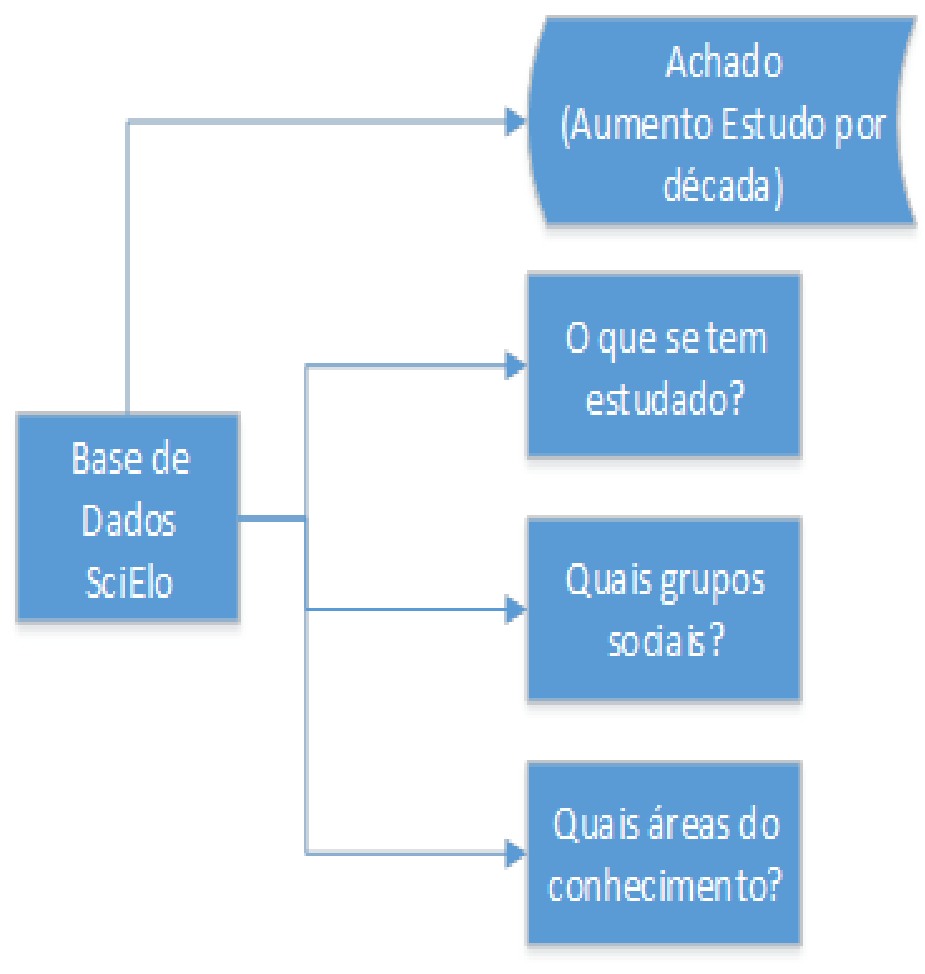

Figura 1 - Questões norteadoras na Base de Dados. (Fonte: Autoria Própria).

Sobre temas de estudo é possível constatar que a área do trabalho tem recebido notoriedade, visto sua capacidade em elevar a produtividade dos funcionários. Observa-se investigações que objetivam identificar variáveis que influenciam os trabalhadores a obterem melhores resultados funcionais, assim como formas para averiguar ações que promovam a saúde no trabalho. Nota-se também estudos que investigam sobre o desemprego e aspectos em torno de trabalho formal e informal. (Figura 2 e Tabela 1). Questões sociais também têm merecido atenção, especialmente por conta de indicadores que correlacionam PIB (produto interno bruto) ao FIB (felicidade interna bruta), de uma nação, na busca por maior desenvolvimento econômico. Os artigos identificados em torno do consumo, comportamento e cultura são de teor crítico quanto à sociedade do consumo. 


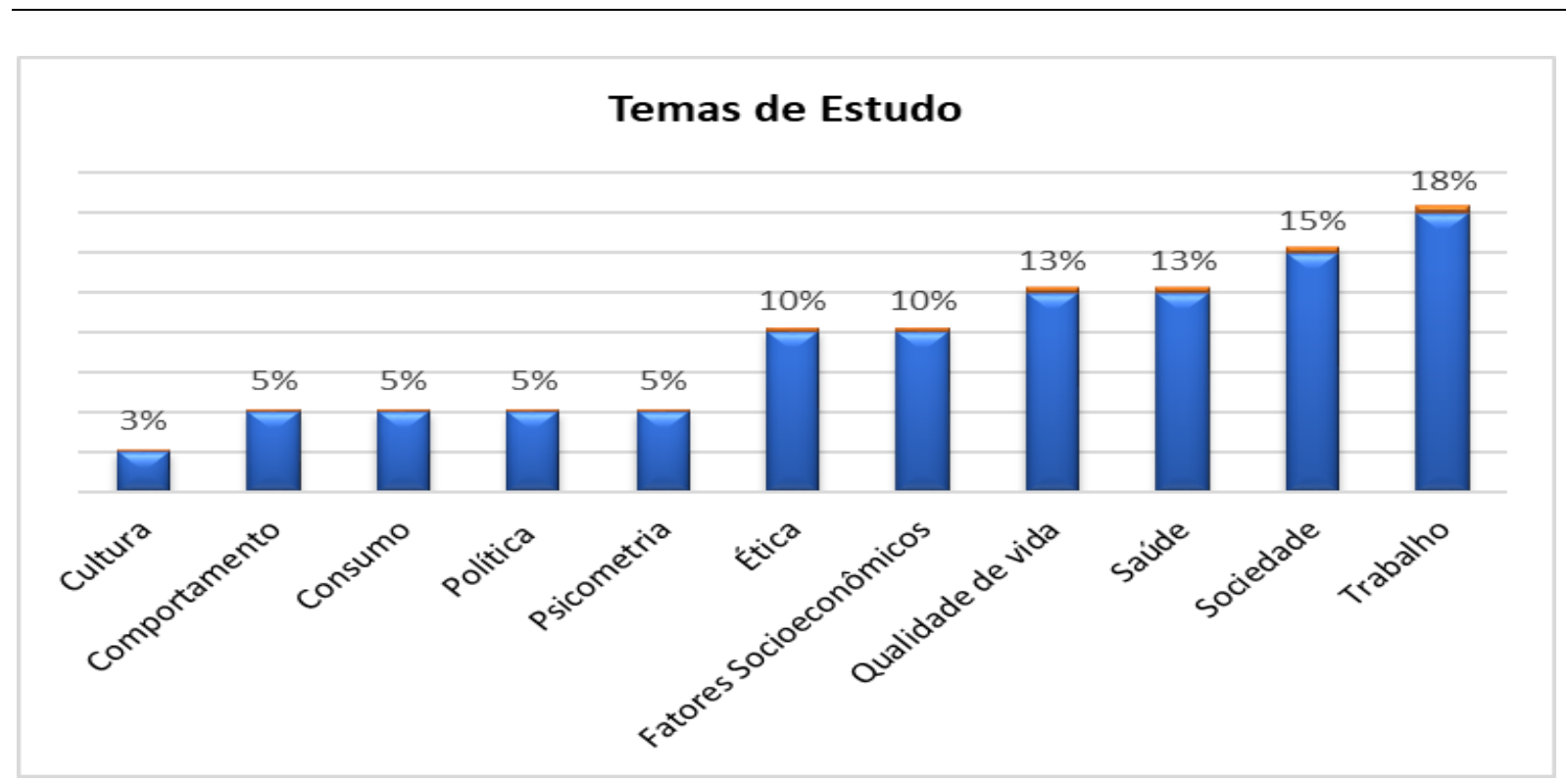

Figura 2 - Frequência e porcentagem - Temas de Estudo. (Fonte: Autoria Própria).

Tabela 1 - Frequência e Porcentagem - Temas de Estudo

\begin{tabular}{lccc}
\hline & Tema & Frequência & Porcentagem \\
\hline Cultura & 1 & $3 \%$ \\
Comportamento & 2 & $5 \%$ \\
Consumo & 2 & $5 \%$ \\
Política & 2 & $5 \%$ \\
Psicometria & 2 & $5 \%$ \\
Ética & 4 & $10 \%$ \\
Fatores Socioeconômicos & 4 & $10 \%$ \\
Qualidade de vida & 5 & $13 \%$ \\
Saúde & 5 & $13 \%$ \\
Sociedade & & 6 & $15 \%$ \\
Trabalho & Total & 7 & $18 \%$ \\
\hline \multicolumn{2}{r}{} & 40 & $100 \%$ \\
\hline
\end{tabular}

Fonte: Autoria Própria.

As pesquisas empíricas identificadas foram realizadas com crianças, adolescentes, idosos, trabalhadores, estudantes, religiosos e demais grupos sociais. (Figura 3 e Tabela 2). Compreende-se que a identificação dos grupos sociais já estudados, fornece subsídios para avaliar os esforços requeridos para empreender novas pesquisas ou continuidade das pesquisas já publicadas ou em desenvolvimento. 


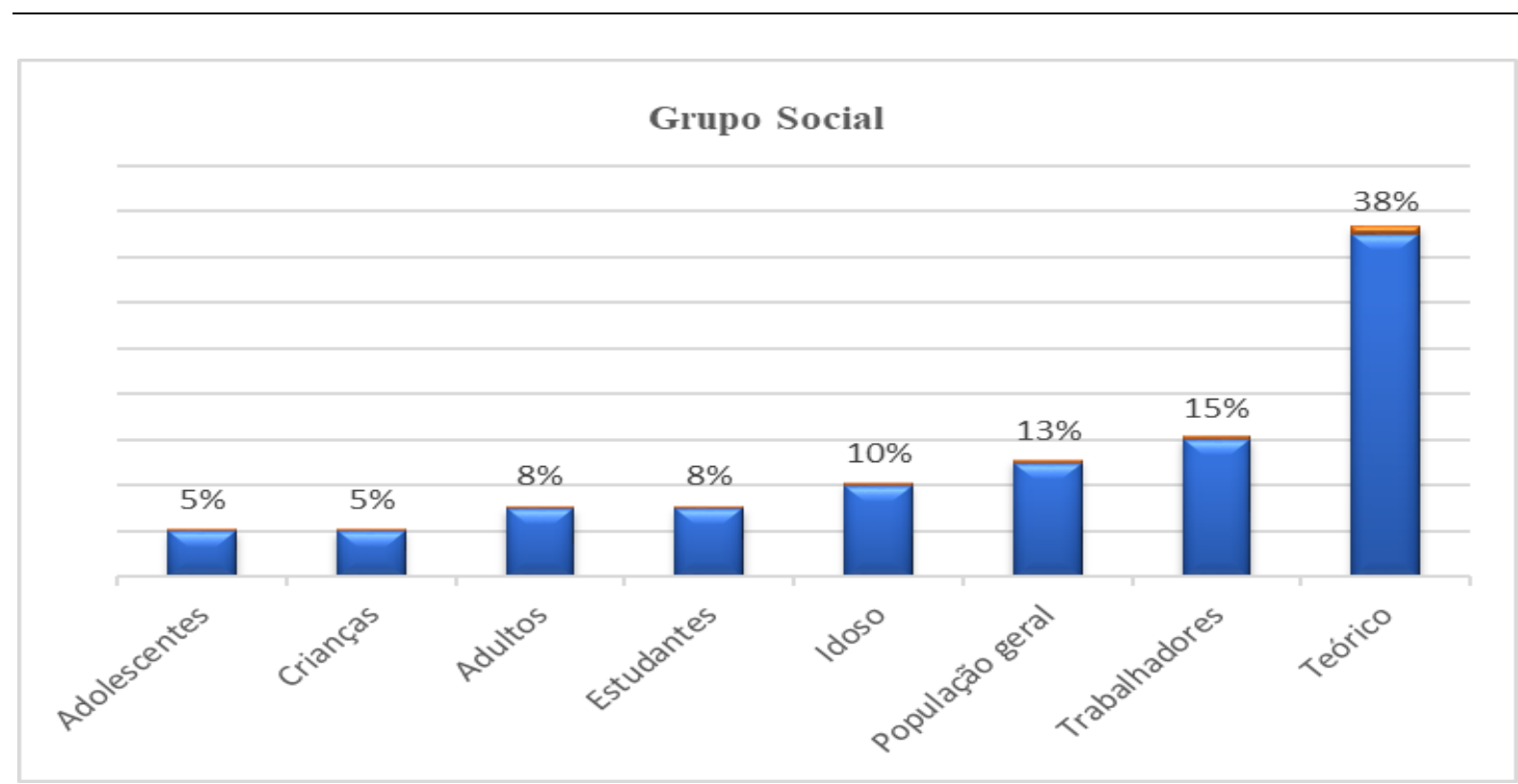

Figura 3 - Frequência e Porcentagem - Grupo Social. (Fonte: Autoria Própria).

Tabela 2 - Frequência e Porcentagem - Grupo Social

\begin{tabular}{ccc}
\hline Ano & Frequência & Porcentagem \\
\hline Adolescentes & 2 & $5 \%$ \\
Crianças & 2 & $5 \%$ \\
Adultos & 3 & $8 \%$ \\
Estudantes & 3 & $8 \%$ \\
Idosos & 4 & $10 \%$ \\
População geral & 5 & $13 \%$ \\
Trabalhadores & 6 & $15 \%$ \\
Teórico & 15 & $38 \%$ \\
\hline Total & 40 & $100 \%$ \\
\hline
\end{tabular}

Fonte: Autoria Própria

Outro apontamento interessante se refere aos pesquisadores interessados no tema felicidade (Figura 4 e Tabela 3). Dos 40 artigos identificados na base de dados SciELO, cujo título contém a palavra felicidade, foi identificado um interesse crescente por diferentes áreas e grupos sociais, assim como o trabalho em pares para a publicação dos artigos, totalizando 49 pessoas envolvidas nas publicações analisadas. Dentre as áreas cita-se a psicologia, educação, economia, direito, ciência dos esportes, ciências da comunicação, engenharia social, nutrição, medicina, dentre outras. Surge novo questionamento: porque diferentes áreas do conhecimento se interessam pelo estudo da felicidade na contemporaneidade? 


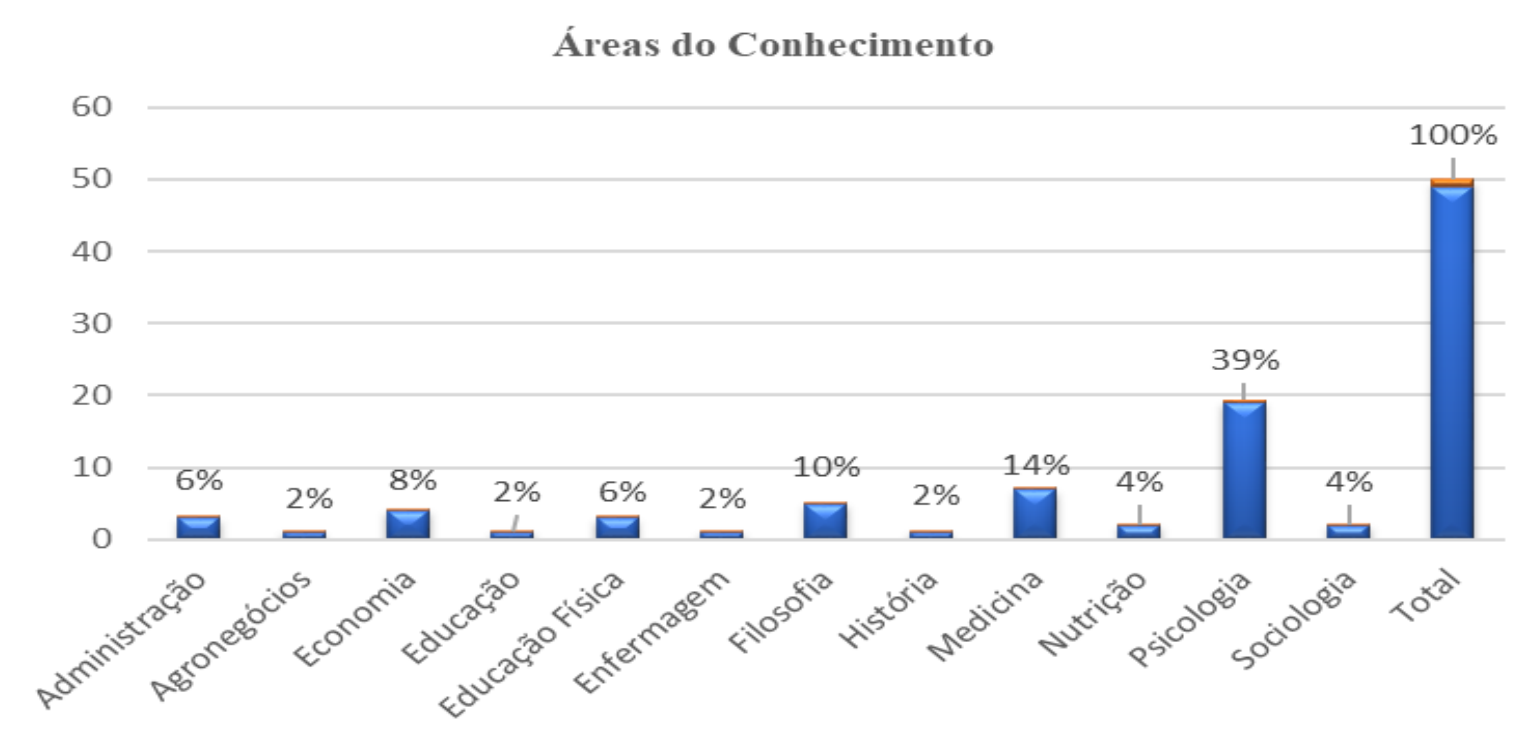

Figura 4 - Áreas do Conhecimento. (Fonte: Autoria Própria).

Tabela 3 - Frequência e Porcentagem - Áreas

\begin{tabular}{lcc}
\hline Ano & Frequência & Porcentagem \\
\hline Administração & 3 & $6 \%$ \\
Agronegócios & 1 & $2 \%$ \\
Economia & 4 & $8 \%$ \\
Educação & 1 & $2 \%$ \\
Educação Física & 3 & $6 \%$ \\
Enfermagem & 1 & $2 \%$ \\
Filosofia & 5 & $10 \%$ \\
História & 1 & $2 \%$ \\
Medicina & 7 & $14 \%$ \\
Nutrição & 2 & $4 \%$ \\
Psicologia & 19 & $39 \%$ \\
Sociologia & 2 & $4 \%$ \\
\hline Total & 49 & $100 \%$ \\
\hline
\end{tabular}

Fonte: Autoria Própria

A questão da ampliação do estudo ao longo das décadas não foi uma informação obtida a partir de um questionamento, emergiu na medida em que os dados foram apurados, podendo ser considerado como um "achado" na pesquisa. Levou ao questionamento: por que o tema felicidade vem sendo estudado com maior intensidade por diferentes áreas e grupos sociais a partir do final do século XX? 
Tabela 4 - Frequência e Porcentagem - Ano

\begin{tabular}{ccc}
\hline Ano & Frequência & Porcentagem \\
\hline 1981 & 1 & $3 \%$ \\
1998 & 1 & $3 \%$ \\
2001 & 1 & $3 \%$ \\
2002 & 1 & $3 \%$ \\
2006 & 2 & $5 \%$ \\
2007 & 1 & $3 \%$ \\
2008 & 3 & $8 \%$ \\
2010 & 5 & $13 \%$ \\
2011 & 4 & $10 \%$ \\
2012 & 5 & $13 \%$ \\
2013 & 6 & $15 \%$ \\
2014 & 6 & $15 \%$ \\
2015 & 3 & $8 \%$ \\
2016 & 1 & $3 \%$ \\
\hline Total & 40 & $100 \%$ \\
\hline
\end{tabular}

Fonte: Autoria Própria

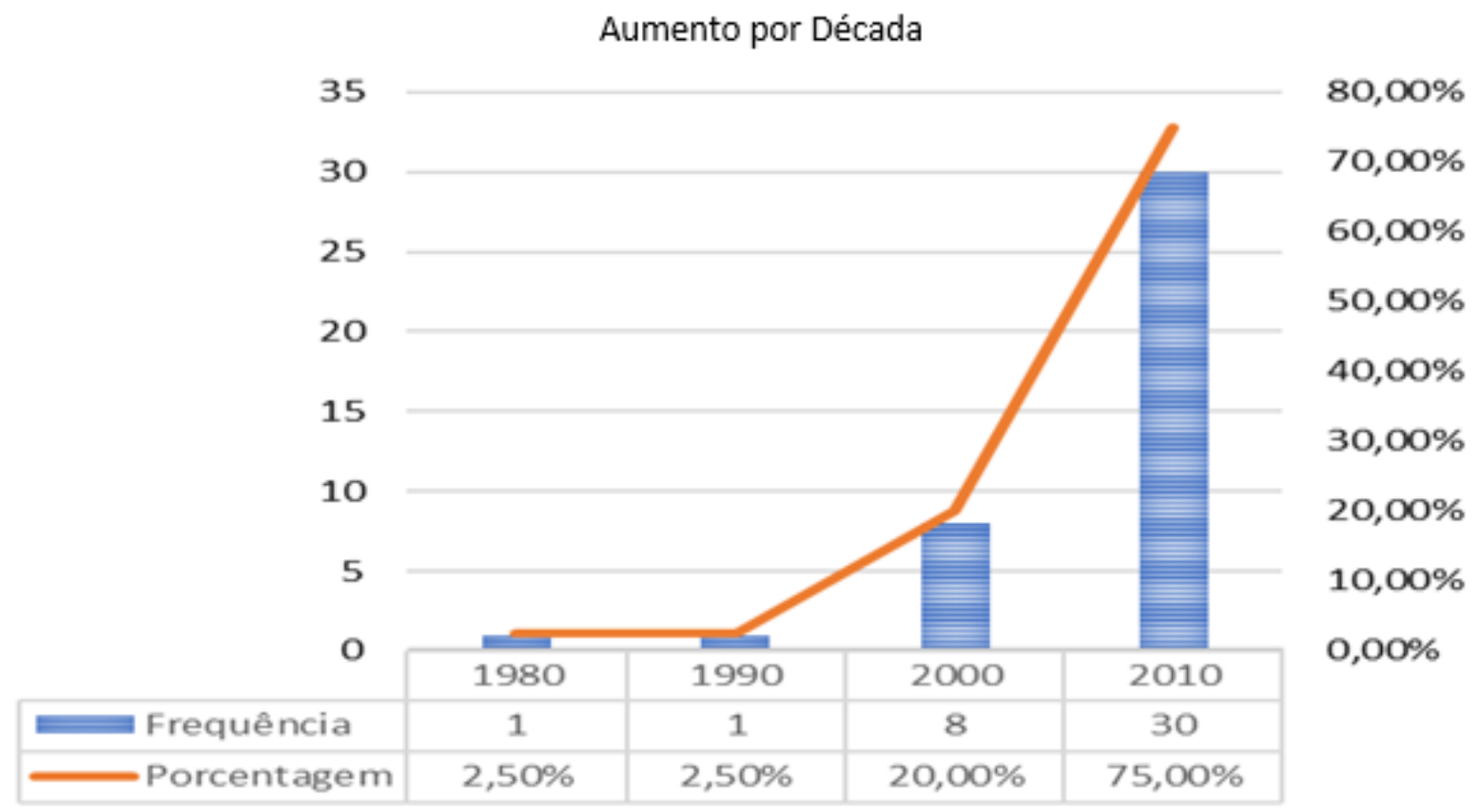

Figura 5 - Frequência e Porcentagem - Década. (Fonte: Autoria Própria). 
Tabela 5 - Frequência e Porcentagem - Década.

\begin{tabular}{ccc}
\hline Década & Frequência & Porcentagem \\
\hline 1980 & 1 & $2,50 \%$ \\
1990 & 1 & $2,50 \%$ \\
2000 & 8 & $20,00 \%$ \\
2010 & 30 & $75,00 \%$ \\
\hline Total & 40 & $100 \%$ \\
\hline
\end{tabular}

Fonte: Autoria Própria

Na Figura 5, é possível reparar que a ampliação do estudo nas últimas décadas se deu de modo paulatino nas publicações identificadas. Pode-se observar na tabela 5 que dois artigos foram publicados entre as décadas de 1980 e 1989 e os demais a partir do ano 2000, sendo publicados oito artigos entre os anos de 2001 a 2008 e trinta artigos de 2010 a 2016 . Na tabela 4 é possível observar como isto se deu por ano.

É sabido que a pesquisa, de modo geral, ampliou-se nas últimas décadas no Brasil e mesmo que ainda seja incipiente, o estudo da felicidade também aumentou. Chama-se atenção quanto ao aumento do estudo sobre felicidade ao longo das décadas. Ao aprofundar um pouco mais sobre esta questão, examinou-se apontamentos específicos concernentes ao aumento de estudos sobre felicidade em função do advento da psicologia positiva, que tem como prática fazer referência à felicidade como "bem-estar subjetivo".

$\mathrm{Na}$ busca por respostas, identificou-se em Greve (2013), um professor de ciências sociais na Universidade de Roskilde na Dinamarca, a menção quanto ao interesse no estudo da felicidade. Ele aponta que tem sido cada vez maior e salienta que corroboram com esta ideia autores interessados no tema, como Synder e Lopes na Psicologia e Veenhoven na Sociologia.

Embora o estudo da felicidade ainda seja recente no Brasil, ao buscar mais conhecimento a este respeito, verificou-se que em outros países o interesse existe há mais tempo. Destaca-se aqui o estudo longitudinal desenvolvido na Harvard Study of Adult Development, gerado a partir do questionamento "How can you live long and happy?". Este estudo iniciou em 1938 nos Estados Unidos e encontra-se na terceira geração de estudiosos. Atualmente está sob a direção de Robert Waldinger, professor de psiquiatria da Harvard Medical School (POWELL, 2012). Desde então outros estudos sucederam.

Ao refletir sobre a palavra felicidade, dentre as categorias analisadas, observou-se o conceito de felicidade. Buscando compreender a forma como a palavra felicidade vem sendo conceituada, ao revisitar os artigos categorizados foi possível constatar que o uso da palavra felicidade é conceituado de diferentes modos entre os autores. Verificou-se também que alguns autores não a conceituam de modo explícito em seus manuscritos.

Observou-se também a menção de diferentes autores acerca da psicologia positiva, enquanto uma área que promove o pensamento positivo como um elemento da felicidade. No manuscrito de Scorsolini-Comin;Santos (2010) os autores mencionam que estudos científicos acerca da felicidade - postulada por eles como "bem-estar subjetivo" (BES) - foram impulsionados com o advento da Psicologia Positiva, focada em promover a saúde e aspectos positivos das pessoas, o que acontece notadamente a partir da década de 1990. Uma das propostas da psicologia positiva para compreender o fenômeno da felicidade com o rigor cientifico necessário, consiste em fragmentá-la, atribuindo ao conceito alguns sinônimos, tais como bem-estar subjetivo, alegria, satisfação e qualidade de vida. 
Estes termos, na concepção de Sewaybricker (2017) não traduzem toda a complexidade que abrange a felicidade. Atento a esta questão, investiga o advento da psicologia positiva e tece reflexões sobre os estudos realizados acerca da felicidade a partir dos construtos supracitados. Dentre seus apontamentos, menciona os esforços da psicologia positiva em romper com o conceito "felicidade" e traduzi-la a partir do conceito arbitrário, "vida boa" e também de "bem-estar subjetivo". Entretanto, reconhece que tem sido uma tarefa difícil de ser realizada em função da repercussão social que a temática da felicidade tende a causar.

Por curiosidade foi levantado na base de dados SciELO.org alguns dos sinônimos atribuídos à felicidade. Ao colocar o filtro "título" foram identificados 57 trabalhos contendo a palavra bem-estar subjetivo como parte do título, 45 estudos com a palavra alegria, 42 com a palavra feliz, dois contendo o termo eudaimonia, $611 \mathrm{com}$ a palavra satisfação e $2024 \mathrm{com}$ as palavras 'qualidade de vida'. Retomamos a palavra felicidade e ao inseri-la como parte do resumo, o resultado muda para 212 artigos na base de dados mencionada.

Ainda que os estudos que investiguem a felicidade enquanto objeto filosófico sejam poucos, nota-se que a menção sobre ela tende a provocar estudos que a abarcam enquanto objeto científico, ou seja, a felicidade tem sido investigada a partir de construtos que a ela remetem.

Dentre os autores que se referem à felicidade como sinônimo de "bem-estar subjetivo", citamos Paschoal; Torres; Porto (2010); Scorsolini-Comin; Santos (2010); Camargo et al (2011); Llobbet et al (2011), Scorsolini-Comin et al (2013). Já Scalco; Araújo; Bastos (2011), seguem a definição de Veenhoven, um sociólogo holandês e professor emérito na Universidade Erasmus de Roterdã, que a descreve como um constructo semelhante à satisfação de vida. Bastos (2012), embora não apresente diretamente o conceito, refere-se à felicidade como sentimento. Ciello (2016) coloca que a felicidade é um resultado do reconhecimento de objetos felizes, Corbi; Menezes-Filho (2006), abarcam que a felicidade algo que está num campo de intersecção entre as dimensões subjetivas e objetivas do bemestar. Remente a novos questionamentos, dentre eles: Porque existem diversos conceitos sobre felicidade? Existe diferença entre eles? Qual seria?

Neste levantamento, foi curioso observar em três artigos publicados por ScorsoliniComin, a forma como se refere ao conceito de felicidade. Em seu artigo publicado no ano de 2009 faz alusão à felicidade como um termo que pode ser associado a muitos conceitos e noções, indicando que o objetivo de o especificar de forma consistente e abrangente trata-se de uma tarefa muito difícil de ser levada a cabo, contudo, o mesmo autor publica outros dois artigos sobre o tema, um em 2010 e o outro em 2013 e nestes apresenta o conceito de felicidade como sinônimo de bem-estar subjetivo. Ao prosseguir na investigação sobre o que é felicidade diferentes estudos foram identificados, dentre eles a dissertação de Sewaybricker (2012), revelando a mudança do conceito de felicidade ao longo dos séculos na perspectiva de oito filósofos atrelando-os aos conhecimentos postulados por Zygmunt Bauman. No estudo, Sewaybricker (2012) considera que não é próprio da felicidade ser objeto de consenso, como consequência, o conceito está fadado a ser constantemente revisto. Neste mesmo teor Fogaça; Perez (2014), também realizam pesquisas buscando compreender as transformações do conceito de felicidade e incitam uma discussão sobre o tema felicidade. O que tem levado a estas mudanças conceituais ao longo dos séculos?

Freire Filho (2010), coloca à ideia de que as obras literárias do passado persuadem aos leitores a considerar a felicidade a partir de determinadas condições e faz observações quanto ao caráter transitório ou ilusório da felicidade terrena e como este permeia a história do pensamento filosófico. De outro modo, na contemporaneidade, alerta sobre as múltiplas 
fontes acadêmicas e midiáticas que irradiam a convicção de que a ciência é capaz de indicar meios para que as pessoas sejam cronicamente felizes, destacando a psicologia positiva formalmente instituída como um movimento científico nos Estados Unidos. Leva ao questionamento sobre como os resultados das pesquisas sobre a felicidade estão sendo utilizados.

Segundo Freire Filho (2010, p.50), a motivação de muitas investigações científicas se refere a "utilidade da felicidade", visto que a felicidade desponta como um recurso estratégico para otimizar a saúde, intervir em questões sociais e até mesmo produtivas. Segundo ele, desde o final de 1990, áreas como a psicologia positiva, a neurociência e os guias leigos de autoajuda, têm realizado investigações científicas seríssimas e frequentemente dispendiosas, encarregando-se de instrumentalizar a utilização da felicidade, redefinindo-a como um potente fertilizante orgânico, como uma espécie de aditivo energético natural, atordoando pessoas frente aos múltiplos benefícios de "ser felizes".

Tal afirmação pode ser observada na obra Felicidade de Bent Greve (2013), enquanto elucida estudos recentes sobre o conceito e a mediação de felicidade com objetivo de sondar e indicar opções que estão além das medidas tradicionais, tais como o PIB (Produto Interno Bruto) para analisar o desenvolvimento de uma sociedade. Para Greve (2013), saber o que torna as pessoas mais felizes não é apenas importante como também central para o desenvolvimento da sociedade. $\mathrm{O}$ autor traz a afirmação de que a busca pela felicidade sem dúvida continuará sendo importante e que os Estados, mercados e sociedade civil precisam ajudar a alcançá-la. É preciso refletir se tal afirmação não seria um tanto quanto equivocada e se de fato é preciso realmente ajudar as pessoas a alcançarem a felicidade. Felicidade trata-se de uma condição, um direito constitucional, um motivo para se viver? Neste caso, não seria pertinente o uso de termos como qualidade de vida ou bem-estar?

Saber o que torna as pessoas felizes, segundo Greve (2013) traz contribuições frente à realização de intervenções em diferentes áreas, tais como sociais e econômicas, de outro modo, ele destaca que nem sempre saber o que torna as pessoas felizes pode ser um problema. Seria realmente preciso tornar as pessoas mais felizes ou esta necessidade em tornar o outro feliz talvez possa se transformar numa armadilha que leva ao direcionamento de ações e intervenções equivocadas, provocando efeitos contrários, tais como a depressão, ansiedade, medo e até mesmo o suicídio? Para Greve (2013), uma boa sociedade é muitas vezes vista como uma sociedade feliz. Mas qual a compreensão que se tem por ser feliz? Não seria antes necessário questionar-se sobre o que é ser feliz?

Em sua obra Greve (2013), abarca sobre o interesse cada vez maior dos pesquisadores no estudo da felicidade. Este apontamento corrobora às constatações obtidas na base de dados SciELO.org, aqui investigadas e faz questionar se a felicidade vem sendo estudada com maior intensidade a partir do final do século XX, por conta da "utilidade da felicidade" postulada por Freire Filho (2010) associada à necessidade de intervenções apresentada por Greve (2013). Quais os efeitos disso?

Ante o suposto vigente "imperativo" da felicidade, é preciso avaliar se isto tem provocado uma sociedade de risco, consumista, depressiva, alienada, estressada, cansada, suicida, angustiada, ansiosa, insatisfeita. A cada dia que passa, são noticiadas matérias sobre eventos que culminam em morte, dor, sofrimento, auto aniquilamento. As crenças sobre felicidade disseminada na contemporaneidade não estão conduzindo à autodestruição, destruição do "outro", da natureza e da vida? Neste teor Lipovetsky (2007), um filósofo francês alerta sobre a ilusão de ser feliz o tempo todo.

Retomando à base SciELO é possível verificar que diferentes grupos sociais têm sido estudados, dentre eles, trabalhadores, idosos, estudantes, adultos, crianças e adolescentes. 
Quanto aos assuntos explorados, a área do trabalho tem recebido maior notoriedade, mas questões sociais, de saúde, qualidade de vida e econômicas também recebem destaque. Áreas como psicologia, educação, economia, direito, ciência dos esportes, ciências da comunicação, engenharia social, nutrição, medicina, dentre outras se interessam pela temática da felicidade. Quais os usos que se tem feito destes estudos?

Cabe aqui legitimar a expressão feita por Orlandi (2002) em "O que estamos ajudando a fazer de nós mesmos". Dentre seus questionamentos é possível deparar com a fatídica pergunta em torno da gravidade da ignorância. Pergunta que pode levar a esquivar das possíveis respostas advindas. Nas palavras de Orlandi, "nunca se viveu tão sistemático cotidiano e envolvente sucateamento da humanidade".

\section{CONCLUSÃO}

Neste manuscrito se apresenta os principais resultados apurados da análise da produção científica brasileira com o intuito de favorecer um movimento que possa surtir efeitos positivos para diversas áreas. Visa-se com isto, promover o acesso acerca da forma como o conhecimento que se tem sobre felicidade vem sendo consolidado, bem como provocar o avanço do conhecimento sobre a felicidade no país.

Frente a análise realizada, de um modo geral, verifica-se que ainda que os estudos sobre felicidade sejam incipientes no Brasil, diferentes áreas do conhecimento têm mostrado interesse crescente em compreender os fenômenos que a ela se relacionam. Dentre os artigos apurados, os contextos pesquisados são diversos, assim como os grupos sociais, as abordagens e problematizações feitas são distintas. Em alguns casos as áreas se integram frente ao desenvolvimento de um mesmo estudo, o que se entende como positivo.

Quanto aos conceitos, estes mostram-se polissêmicos. De um ponto de vista amplo, são apresentados sumariamente a partir de sinônimos, tais como: bem-estar subjetivo, alegria, satisfação e qualidade de vida sob a influência da psicologia positiva.

Ao explorar os estudos com estas terminologias e também inserir as palavras satisfação e qualidade de vida no mecanismo de busca da base aqui investigada, reparou-se que a ampliação dos estudos acontece de modo significativo. De outro modo, nota-se que alguns autores não fazem menção de modo explícito quanto ao conceito escolhido para delinearem suas pesquisas.

Outra questão que sobressaiu em alguns artigos foi a menção quanto ao despontar da psicologia positiva e sua relação com os estudos crescentes que visam investigar a felicidade, sob o aporte de construtos que a ela fazem referência. Observa-se que decorre da necessidade de se obter o rigor científico necessário, aliada à dificuldade em mensurar a felicidade.

Destaca-se a fragmentação da felicidade a partir dos estudos da psicologia positiva com o uso de termos que a referenciam, conduzindo ao distanciamento de discussões filosóficas necessárias sobre ela. Esclarece-se que a psicologia positiva tem trazido importantes mudanças e avanços nos estudos referente às emoções e ao comportamento humano em termos construtivistas e não patológicos, sobretudo no que se refere a questões que envolvam "viver-se uma boa vida".

Porém, cabe a ressalva de que ao debruçar-se para compreender estudos que tratam sobre felicidade a partir de uma visão aristotélica, é possível averiguar-se que viver uma boa vida refere-se a um "meio" para obter a felicidade, mas não trata sobre toda a complexidade que a envolve.

Salienta-se que a psicologia positiva tem reconhecido a necessidade em utilizar outros termos que não a felicidade, embora tenha sido uma empreitada uma tanto quanto árdua em 
função da repercussão social que a temática da felicidade tende a causar.

Outro aspecto que chamou atenção nesta revisão, refere-se ao fato de que a área do trabalho tem recebido notoriedade no que concerne à maior demanda de estudos sobre felicidade ou termos correlatos. Pesquisas que envolvem a interface indivíduo e organização têm buscado apurar mecanismos que promovam motivação, bem-estar e saúde no trabalho. Ainda assim, constatou-se dentre os autores abrangidos nesta revisão, a necessidade de mais pesquisas que explorem a relação entre felicidade e trabalho.

Dentre os autores abrangidos neste estudo, foi possível averiguar a alusão a respeito da "promessa de felicidade" promovida pela indústria em suas diferentes interfaces, capaz de provocar o acúmulo do sofrimento coletivo. Nesse compasso, entende-se ser primordial o estabelecimento de uma relação equilibrada do indivíduo consigo mesmo, verificando parâmetros necessários para uma vida digna, dissociada da ilusão de uma felicidade que nunca se sacia. Neste teor, considera-se a necessária reflexão sobre o que se entende por felicidade, bem como refletir sobre a produção de conhecimento quanto a felicidade.

Como limitação deste estudo, reconhece-se que ao envolver artigos de diferentes nacionalidades, é preciso se atentar quanto a compreensão do conceito da felicidade em função dos aspectos culturais de cada país. Em contrapartida, pode revelar uma oportunidade para prosseguir com as investigações aqui expostas a partir deste prisma.

Por fim, reconhece-se a necessidade de prosseguir com este estudo e integrar outras bases de dados a fim de apresentar um panorama sobre a felicidade em âmbito nacional, para tanto, sugere-se envolver aspectos em torno do seu crescimento nas últimas décadas, principais áreas interessadas, como vendo sendo conceituada, dentre outras questões. Posteriormente recomenda-se prosseguir com as investigações junto a base de dados de outros países.

\section{REFERÊNCIAS}

ARISTÓTELES. Ética a Nicômaco. Tradução de António de Castro Caeiro. São Paulo: Atlas, 2009.

BASTOS, C. C. et al. Importância atribuída ao sexo por idosos do município de Porto Alegre e associação com a autopercepção de saúde e o sentimento de felicidade. Rev. bras. geriatr. gerontol. [online]. 2012, vol.15, n.1, pp.87-95. ISSN 1981-2256. http://dx.doi.org/10.1590/S1809-98232012000100010.

CAMARGO, S.P.H.; ABAID, J.L.W. e GIACOMONI, C. H. Do que eles precisam para serem felizes? a felicidade na visão de adolescentes. Psicol. Esc. Educ. [online]. 2011, vol.15, n.2, pp.241-250. ISSN 2175-3539. http://dx.doi.org/10.1590/S141385572011000200006 .

CIELLO, Fernando José. Feminist killjoys e reflexões (in)felizes sobre obstinação e felicidade. Rev. Estud. Fem., Florianópolis, v. 24, n. 3, p. 1019-1022, dez. 2016. http://dx.doi.org/10.1590/1806-9584-2016v24n3p1019.

CORBI, Raphael Bottura; MENEZES-FILHO, Naércio Aquino. Os determinantes empíricos da felicidade no Brasil. Rev. Econ. Polit, São Paulo, v. 26, n. 4, p. 518-536, dez. 2006. http://dx.doi.org/10.1590/S0101-31572006000400003. 
FOGAÇA, J., PEREZ, C. Felicidade adjetivada: polifonia conceitual, imperativo social. Intercom, Rev. Bras. Ciênc. Comun., São Paulo , v. 37, n. 1, p. 217-241, June 2014. http://dx.doi.org/10.1590/S1809-58442014000100011.

FREIRE FILHO, J. A felicidade na era da sua reprodutibilidade científica: construindo "pessoas cronicamente felizes". In: FREIRE FILHO, J. (Org.). Ser feliz hoje: reflexões sobre o imperativo da felicidade. Rio de Janeiro: FGV, 2010. p.49-82.

GOMES, I. S.; CAMINHA, I. O. Guia para estudos de revisão sistemática: uma opção metodológica para as Ciências do Movimento Humano. Movimento, v. 20, n. 1, p. 395-411, 2014.

GREVE, B. Felicidade. São Paulo: Unesp, 2013.

LIPOVETSKY, G. A felicidade paradoxal: ensaios sobre a sociedade de hiperconsumo. Trad. Maria Lúcia Machado. São Paulo: Companhia das Letras, 2007.

LLOBET, M.P. et al. Qualidade de vida, felicidade e satisfação com a vida em anciãos com 75 anos ou mais, atendidos num programa de atenção domiciliária. Rev. Latino-Am. Enfermagem, Ribeirão Preto, v. 19, n. 3, p. 467-475, jun. 2011. http://dx.doi.org/10.1590/S0104-11692011000300004.

MUELLER, Suzana Pinheiro M. A Comunicação científica e o movimento de livre acesso ao conhecimento. Ciência da Informação, Brasília, DF, v. 35, n. 2, 2006. https://doi.org/10.18225/ci.inf. v27i1.826

ORLANDI, L. "O que estamos ajudando a fazer de nós mesmos". In: RAGO, M.; ORLANDI, L.; VEIGA-NETO, A. (orgs). Imagens de Foucault e Deleuze: ressonâncias nietzscheanas. Rio de Janeiro: DP\&A, 2002.

PASCHOAL, T.; TORRES, C.V; PORTO, J.B. Felicidade no trabalho: relações com suporte organizacional e suporte social. Rev. adm. contemp. Curitiba, v. 14, n. 6, p. 1054-1072, dez. 2010. http://dx.doi.org/10.1590/S1415-65552010000700005.

POWELL, A. (2012, 2 de Fevereiro). Decoding Keys to a Healthy Life. Harvard Gazette, disponível em http://news.harvard.edu/gazette/story/2012/02/decoding-keys-to-a-healthy-life/

SCALCO, D.L.; ARAUJO, C.L.; BASTOS, J.L. Autopercepção de felicidade e fatores associados em adultos de uma cidade do sul do Brasil: estudo de base populacional. Psicol. Reflex. Crit., Porto Alegre, v. 24, n. 4, p. 648-657, 2011. http://dx.doi.org/10.1590/S010279722011000400004

SCORSOLINI-COMIN, F. A felicidade paradoxal: ensaios sobre a sociedade de hiperconsumo. Psicol. estud., Maringá, v. 14, n. 1, p. 203-204, mar. 2009. http://dx.doi.org/10.1590/S1413-73722009000100024.

SCORSOLINI-COMIN, F.; SANTOS, M.A. O estudo científico da felicidade e a promoção da saúde: revisão integrativa da literatura. Rev. Latino-Am. Enfermagem, Ribeirão Preto, v. 
18, n. 3, p. 472-479, jun. 2010. http://dx.doi.org/10.1590/S0104-11692010000300025.

SCORSOLINI-COMIN, F. et al. From authentic happiness to well-being: the flourishing of Positive Psychology. Psicol. Reflex. Crit., Porto Alegre , v. 26, n. 4, p. 663-670, dez. 2013. http://dx.doi.org/10.1590/S0102-79722013000400006.

SEWAYBRICKER, L.S. A felicidade na sociedade contemporânea: contraste entre diferentes perspectivas filosóficas e a modernidade líquida. Dissertação (Mestrado em Psicologia Social). Instituto de Psicologia Social e do Trabalho, Universidade de São Paulo, SP, 2012.

Felicidade: utopia, pluralidade e política. A delimitação da felicidade enquanto objeto para a ciência. Tese (Doutorado em Psicologia Social). Instituto de Psicologia Social e do Trabalho, Universidade de São Paulo, SP, 2017.

SCHWEITZER, F.; RODRIGUES, R. N. S. Produção científica em áreas multidisciplinares: educação a distância no brasil. Em Questão, v. 19, n. 1, Em Questão, 2013, pp. 156-172. Universidade Federal do Rio Grande do Sul, Porto Alegre, Brasil. http://dx.doi.org/10.19132/1808-5245191.156-172. 